\title{
EL GRAFITI EN LA ERA DIGITAL
}

\author{
Marta del Pino Méndez
}

Universitat de les Illes Balears

\begin{abstract}
Resumen: Este trabajo aspira a conocer el encaje de la práctica del grafiti en el mundo digital. Delimitado el grafiti como manifestación a la manera neoyorquina y desde el estudio del contexto local radicado en Mallorca, se pretende un acercamiento a sus ventajas y desventajas en la actual era digital y al conocimiento de la medida en que el grafiti está adaptado a su uso. Las nuevas posibilidades de difusión, la huella digital, la cuestión de la originalidad en el mundo globalizado son temas que se abordan en este texto y que pretenden poner el foco en una práctica que conforma un acto de comunicación en los muros del que nadie está excluido, aunque su participación se vea limitada a la de simple espectador.
\end{abstract}

Palabras clave: grafiti, escritor, era digital, difusión, Mallorca, arte.

\section{The grafitti in the digital world}

Abstract: This work pretends to know the socket of the practice of graffiti in the digital world. Delimited graffiti as the New York way and from the study of the local context in Mallorca, an approach to the advantages and disadvantages of this digital age and the knowledge of the extent to which the graffiti is adapted to its use. New possibilities for dissemination, the fingerprint, the question of originality in the globalized world are topics that are dealt with in this text and seeking to put focus on a practice that constitutes an act of communication on the walls of which no one is excluded, although their participation be limited to the simple viewer.

Key words: graffiti, writer, digital world, dissemination, Majorca, art.

\section{INTRODUCCIÓN}

El presente trabajo pretende abordar el encaje de la práctica del grafiti en el mundo digital. Para este caso concreto, entendemos el grafiti únicamente como la modalidad iniciada en los años setenta del siglo XX en la ciudad de Nueva York, expandida de forma pandémica al resto del mundo (Figueroa, 2006, 47). Dicha modalidad recibe el nombre de grafiti de firma o hip hop por sus vinculaciones con la subcultura del hip hop. En 2019 la Real Academia de la Lengua Española ${ }^{1}$ define grafiti (en su voz hispana, con una sola f) como

Data de recepció: 15 d'abril de 2020 / Data d'acceptació: 4 de maig de 2020.

1 https://dle.rae.es/grafiti 
"firma, texto o composición pictórica realizados generalmente sin autorización en lugares públicos, sobre una pared u otra superficie". Si bien es una buena explicación debemos añadir ciertos componentes que la completen para terminar de describir con mayor precisión esta manifestación. Una de las más completas definiciones al respecto la aporta Fernando Figueroa $(2004,18)$ al apuntar, entre otras cuestiones, que:

se realiza manualmente, con auxilio o no de instrumentos o maquinaria, con técnicas directas (pintada, aerosol, grabado, etcétera), generalmente, sobre un soporte fijo, portátil o móvil (dimensión itineraria), estable o inestable.

También Javier Abarca $(2010,35)$ aporta lo siguiente:

El comportamiento artístico no comercial por el cual el artista propaga sin permiso en el espacio público muestras de su producción, utilizando un lenguaje visual inteligible para el público general, y repitiendo un motivo gráfico constante o bien un estilo gráfico reconocible, de forma que el espectador puede percibir cada aparición como parte de un continuo.

Con todo ello nos encontramos ante un práctica que se realiza mediante la firma -bajo seudónimo-, con o sin texto y con o sin un motivo pictórico, cuyo útil de realización es el aerosol -de forma mayoritaria-, por la cual no hay ningún tipo de acuerdo contractual, que repite motivo -firma- con distintas caligrafías o estilos siendo ambos reconocibles igualmente para los iniciados y que cuentan con un soporte de diversa naturaleza pero que comparten la cuestión de ser ajeno al grafitero. Así pues, hablaremos en este caso de grafiti refiriéndonos a esta tipología.

Este grafiti llega a España -y a Mallorca- a finales de la década de los ochenta del siglo XX (Figueroa, 2006, 93-94), consolidándose en los noventa y manteniéndose vigente actualmente.

Ciertamente hoy día convive con nuevas formas de expresión en el entorno urbano (stickers, Street art, Urban art, etc.), que excluimos para el presente texto porque abordar ahora este conjunto de prácticas resultaría inabarcable e inasumible por su diversidad.

Ciñéndonos a la tipología citada nos aproximaremos a cuestiones como la globalización, la legalidad o la originalidad en el contexto del grafiti intentando esclarecer su alcance. Interesa conocer las circunstancias en las que hoy día se produce y reproduce el grafiti desde el muro para el mundo, así como acercarse a las cuestiones negativas que se derivan de la sobreexposición y la huella digital o la cuestión de la originalidad que puede verse perjudicada en un mundo donde todo está digitalizado. 
Este trabajo nace en el ámbito local de la isla de Mallorca y de ella se nutren muchos de los ejemplos y autores que a lo largo del texto ilustrarán cuestiones concretas, no obstante, el punto de vista va desde lo local hacia lo nacional e incluso internacional. Es por ello que las referencias directas a la Isla serán escasas. En el caso de la globalización, Mallorca no ha tomado una posición distinta al resto del globo y sus grafiteros tampoco difieren de los que hallamos en Madrid o en México, por poner ejemplos. Las cuestiones desgranadas en el texto afectan a todos por igual, estén donde estén siempre que tengan una conexión a la red.

Para analizar con mayor detalle el tema que nos ocupa, el texto se ha organizado atendiendo a diversas cuestiones que se inician con una base preliminar que pretende contextualizar el fenómeno del grafiti, continúa con una síntesis de sus rasgos fundamentales y una breve reflexión pero a nuestro juicio trascendental sobre su incursión en la era digital y en la globalización mediante el recurso a aspectos imprescindibles de la disciplina. Finalmente el estudio se cierra con unas consideraciones últimas que ahondan sintéticamente en los aspectos nucleares y en su relación imprescindible y presumiblemente rica del grafiti inmerso en su expansión mundial gracias a las redes sociales y a la creación de archivos digitales.

\section{CIERTAS CONSIDERACIONES PRELIMINARES: POR UNA CONTEXTUALIZACIÓN DEL GRAFITI}

En la era digital actual el mundo es una pantalla. A golpe de clic accedemos a toda suerte de información, pero también la emitimos de toda clase, siendo este uno de los aspectos más relevantes de la vida digital -y digitalizada-. Gracias a internet y su democratización hemos conseguido reducir el mundo a unas pocas pulgadas, las que tiene un smartphone. La inmensidad reducida en un dispositivo que cabe en un bolsillo.

Comprimir el mundo en un dispositivo móvil ha permitido acceder en cualquier momento y sin necesidad de ningún otro objeto accesorio a casi cualquier recurso. Nuestra vida y nuestros patrones de conducta social han sentido $-\mathrm{y}$ resentido- esta transformación. Todo es susceptible de hacerse en línea, no es preciso ubicarse en un lugar concreto porque vivimos en la red o estableciendo un paralelismo en un posible no-lugar expuesto por Bauman $(2004,111)$. Este no-lugar es virtual, pero del mismo modo que los que desarrolla el filósofo, acepta la inevitabilidad de una permanencia prolongada de extraños porque los unifica bajo unos mismos códigos de conducta. Todo el mundo se siente en su casa, aunque nadie debe comportarse como si estuviera en su casa. 
En esta sociedad cambiante, ubicada en la posmodernidad o en la neo-modernidad del 2, 3 o 4.0, nuestros dispositivos móviles son todo aquello que necesitamos, y no solo para acceder a información sino también para generar información. La exposición pública de la persona se ha visto magnificada en esta era digital. La privacidad es, a todas luces, un concepto en decadencia. Eres en función de tu exposición virtual, ergo, si no te expones, no eres.

En esta libertad digital de las redes de comunicación, ¿cuál ha sido la reacción del grafiti? Quizá la única posible, esto es, la aceptación, adaptación y el aprovechamiento. El grafiti ha sido capaz de mostrarse permeable a la conectividad y ha sabido sacarle todo el partido posible al fenómeno de la conexión mundial.

Se pueden distinguir dos causas fundamentales que han llevado al grafiti a posicionarse como aliado de la era digital y a servirse de sus beneficios. En primer lugar, la edad de los "escritores". Por lo general, y tomando como referencia las aportaciones hechas por grafiteros de Mallorca como Lais o Hock, entre otros, la vida de un grafitero activo abarca desde los 15 años hasta los 18 o 20 años. Pueden darse casos de inicio previo, entre los 13 o 14 años, y que la vida en activo se prolongue, como se plasma en grafiteros de Mallorca, activos con una edad superior a los 30 años, como son OVAS y NASE, considerados ya históricos por que se iniciaron en 1989 y aún se mantienen. La juventud es a priori más permeable a las nuevas maneras de expresarse y también a las nuevas plataformas. Además los escritores más jóvenes nacen ya en un contexto digital, por lo que les resulta natural el uso de las herramientas que tienen a su alcance. En segundo lugar, la era digital funciona como un altavoz conectado a todo el mundo. Las posibilidades de difusión son infinitas, y eso es para el grafiti una cuestión fundamental. Ser en función de la exposición. Eso es el grafiti.

Marcamos el inicio de la aparición del grafiti en los años 60 y 70 del siglo XX en Nueva York, llegando a España a fines de los 80 y principios de los 90. En todo ese tiempo, la esencia del grafiti se ha mantenido impermeable a los cambios. En este juego del grafiti, como ya se ha dicho, eres si te expones, si te dejas ver. Eres escritor de grafiti si tu firma se ve en la ciudad, si tu firma alcanza tanto territorio que lo dominas de forma visual. Es decir, eres si te ven. Del mismo modo que en la vida en red, en el grafiti impera la exaltación del ego. No es una práctica realizada para quedar oculta, porque el grafiti, en palabras de los escritores Lais y Sem, es la manifestación humana más primaria del ego. A tal efecto escribe la estudiosa Leila Gándara $(2002,11)$ :

Conceptualmente, el graffiti evoca una acción muy primitiva, la de los primeros trazos del hombre en la piedra de las cavernas. Desde entonces, la humanidad no ha cesado de dejar su rastro en las paredes: un encuentro de lo perenne y lo efímero, en el que el cuerpo imprime su huella en un material destinado a perpetuarla. 
Debemos apuntar que el grafiti es, entre otras cosas y por encima de ellas, un acto de comunicación donde confluyen varios actores. El escritor emite un mensaje, su firma, y a partir de aquí se desencadenan dos receptores. De un lado, los receptores pasivos, ciudadanos que conviven de forma ajena al mensaje lanzado, los cuales sin saberlo forman parte de un juego comunicativo ya que de un modo u otro tomarán partido: bien les gustará, bien les horrorizará, y eso conformará su posterior respuesta a este lenguaje singular. En este sentido, podemos discrepar de las tesis de Djukich y Finol (1996), quienes en Semiótica del discurso amoroso: Graffiti en la Prensa denominan a dichos receptores espectador vicario, porque consideran que la función del espectador no es la recepción sino únicamente la de ser testigo. De otro lado, el receptor activo, otros escritores. Estos acogerán con ánimos diferentes el mensaje lanzado: despertará alegrías y se sucederán grafitis de apoyo entre sus simpatizantes -normalmente miembros de la misma familia de escritores, como veremos más adelante-, mientras que otros escritores de familias diferentes (e incluso de familias rivales) lo tomarán como un reto o desafío y se lanzarán a dejar sus propios mensajes para intentar sobresalir en el juego.

En este acto comunicativo ha habido desde los inicios disparidad de criterios, sobre todo por la cuestión del anonimato de los emisores de los mensajes, lo que ha llevado a algunos autores (Gándara, 2002, 55) a afirmar que nos encontrábamos ante comunicaciones defectuosas; sin embargo, para Garí (1995) no existe tal problema, que es la tesis que también defendemos, esto es, que el grafiti en un acto de comunicación. Así Garí $(1995,90)$ afirma que:

el anonimato mutuo entre productor y receptor no tiene que ocasionar necesariamente ninguna deficiencia desde el punto de vista comunicativo: sería así en el caso de que lo implicado fuera una cuestión estrictamente informativa (...). Desconocer la identidad empírica del autor, en efecto, no es una particularidad del graffiti, sino que es un rasgo constitutivo de muchos discursos, como el publicitario, o el proverbial.

\section{CARACTERÍSTICAS BÁSICAS DEL GRAFITI}

En el apartado precedente ya se han citado tres rasgos básicos del grafiti: la cuestión de la edad temprana como momento importante en que el grafiti arraiga, el tema de la exaltación del ego, que resulta asimismo una característica fundamental de esta manifestación, y el anonimato como forma de vivir el grafiti. Sin embargo, como toda disciplina compleja hay muchos otros rasgos que pueden entrar en la definición. En los siguientes párrafos introduciremos refe- 
rencias a cuestiones que resultan capitales, como la elección del seudónimo, el desarrollo de la técnica y la caligrafía hasta conformar un estilo propio y la capacidad asociacionista del grafiti.

No obstante, ahora hemos de ahondar en tres cuestiones sin las que el grafiti se vería despojado de su esencia, a saber: la ilegalidad, el soporte y el material.

En primer lugar, la ilegalidad, que es vista como la condición sine qua non, su razón de ser. La firma de un escritor debe realizarse en espacios públicos no permitidos. Todos los escritores consultados hasta la fecha coinciden en considerar que este aspecto es fundamental. En el momento en que un muro es de uso legal deja de ser un espacio digno de una firma².

La segunda característica está ligada a la primera, ya que el grafiti debe suponer una transgresión, una conquista, una usurpación. Los escritores con su firma se apoderan de cualquier espacio a su disposición. A tal efecto y aunque hay unos soportes que gozan de mayor prestigio, al escritor le sirven tanto paredes como las que Joan Garí $(1995,22)$ denomina "sus extensiones metonímicas": puertas, muebles, árboles, vagones de trenes y un sinfín de etcéteras entre el mobiliario urbano habitual.

En tercer y último lugar, hay que citar los materiales que utiliza, que son invariablemente el aerosol (rey indiscutible, ya que su uso y dominio requiere habilidad y práctica) y el rotulador (accesorio inicial de principiantes y elemento fundamental para soportes plásticos y de pequeño tamaño).

Estas características, aunque muy resumidas, son la esencia del grafiti, y sirven para conformar un marco inicial desde el que trabajar. Como se ha comentado, el grafiti se ha mantenido impermeable a los cambios, esto es, firme e inflexible en lo tocante a sus señas de identidad (aerosol, rotulador, obras a mano alzada, bocetado previo).

Y es que el grafiti toma conciencia de su mortalidad (por la exposición pública del soporte y por la censura social) y no hace nada por evitarlo (a nivel técnico), pero encuentra en la digitalización la herramienta para hacer de su actividad efímera un arte perdurable. El escritor de grafiti, sabiendo que su firma o pieza va a ser efímera (en la mayoría de los casos), se conforma con realizarla y fotografiarla para así poder mirarla y enseñársela a aquellos que por la razón que sea no la hayan visto. Ellos mismos realizan su propio álbum fotográfico que después les servirá para rememorar misiones y piezas realizadas. La ausencia de permeabilidad convierte al grafiti en una práctica tradicional

2 "El día que me permitan pintar, el día que sea legal y no me persiga un [guardia] jurado por las vías... ese día lo dejaré"; fragmento extraído de https://www.elespanol.com/ reportajes/20180704/grafiteros-aterrorizan-conductores-barcelona-piedras-pistolas-taser/319 719019_0.html Visualizada en: 30-01-2019 a las 20:42h. 
(y hasta cierto punto tradicionalista, ya que hay mucha ortodoxia y purismo en el mundo grafitero) que únicamente ha incorporado aquello que le ha convenido de cuanto ha sucedido en el mundo. Además, se puede afirmar que es una práctica de base artesanal. El grafiti consiste en el perfeccionamiento de una técnica, la depuración de un estilo y la asimilación de unos recursos que permitan realizar un trabajo rápido e impactante. Todo ello se trabaja a conciencia en el denominado black book, esto es, antes de salir a las calles. Ese black book es al final una libreta de bocetos, esquemas y tipografías. Solo en el momento en que la técnica esté asumida se podrá ver en la calle.

Volviendo al mundo global, tanto la globalización como la era digital vienen a dinamitar las fronteras territoriales y el grafiti encuentra en este mundo sin fronteras un aliado fundamental. Juan Ángel Jódar Marín $(2010,5)$ afirma que "los nuevos medios diluyen las barreras divisorias de los soportes y los formatos de contenidos constituyendo nuevas realidades mediáticas que solo tienen sentido en un entorno digital".

Por tanto, los nuevos medios disuelven barreras de soportes y de contenidos, derribando a nivel mundial las acostumbradas trabas. Las fronteras territoriales a gran escala entre países son, en su medida más reducida, los muros de cada rincón de la ciudad y estos desaparecen al juntar elementos tan habituales ya en nuestras vidas como la relación cámara fotográfica+internet+red social. Nuestros teléfonos móviles cuentan con una cámara fotográfica (cada vez con mayor resolución de imagen), una red de internet que nos permite recibir e importar datos a gran velocidad y enlaces a diversas redes sociales en las que nos comunicamos de forma constante tanto con conocidos como con desconocidos de cualquier rincón del mundo. Las posibilidades generadas se han vuelto ilimitadas a la hora de comunicar y comunicarnos.

\section{LA COMUNICACIÓN EN EL MUNDO GLOBALIZADO}

En el mundo global se multiplican de forma infinita los emisores y los (dos tipos) de receptores. Una firma en Brasil puede tener ahora su respuesta en un muro de un barrio de Tokio en cuestión de segundos. El grafiti puede hacerse viral, expandirse y exponerse con una rapidez nunca imaginada por aquellos pioneros de los 60 y 70 del siglo pasado, quienes veían el éxito del reconocimiento en un tren con su firma recorriendo la ciudad ${ }^{3}$. De este modo el grafiti obtiene un gran aprovechamiento de las redes. Ahora, el grafitero/escritor cuenta

3 Vid. https://www.youtube.com/watch?v=NFBRfhoAB1Q min. 05:36-06:10. Visualizado en 05-01-2019 a las 15:10h. 
con su dispositivo móvil, con su cámara incorporada y una conexión de datos móviles que le permitirá documentar toda su actividad desde la elección de los aerosoles, las boquillas, el proceso de realización de la pieza hasta la obra terminada. Todo ello será importado y visualizado a una velocidad fulminante.

Un claro ejemplo de esa inmediatez es la plataforma Instagram donde se suceden múltiples cuentas de escritores y de crews (asociación entre escritores en forma de grupo). En ella es fundamental la capacidad para usar los hastags adecuados y hacer así que una sola imagen llegue a más personas. Saber asignar las palabras clave a cada imagen resulta esencial para alcanzar un mayor número de visualizaciones. Además de Instagram otros medios disponibles más utilizados son Facebook y YouTube. Prácticamente todos los escritores tienen sus cuentas particulares como escritores, y las tienen asociadas a su crew por lo que resulta sencillo seguir la pista de escritores y crews de todo el mundo.

A todo ello se le añade otra ventaja inimaginable: el asociacionismo. El grafiti es en primera instancia un juego individual, ya que el escritor tiene total control sobre su firma y por ende sobre su seudónimo; sin embargo, se asocia con otros escritores casi desde el primer momento en que empieza, ya que, pese al individualismo pujante, ser parte de un colectivo le hace ganar fuerza y le granjea ayudas muy necesarias. Nunca se deja a nadie atrás y aunque un integrante realice una pieza en solitario con su seudónimo siempre pondrá en algún lugar visible el nombre de su crew, dejando claro a otros escritores que no está solo y que hay un grupo que respalda sus acciones.

Estas se unen para compartir experiencias, realizar piezas de gran tamaño, acompañarse en incursiones a la ciudad y para retroalimentarse. El nombre que adquieren siempre es breve en forma de acrónimo, iniciales que aparecerán en todas las piezas de sus integrantes y que serán protagonistas también en piezas propias. Formar parte de una crew es objetivo fundamental del grafitero que empieza, así como mantenerse y crear nuevas es el objetivo de aquellos más experimentados.

Estas crews funcionan como una especie de familias-hermandades con jerarquías propias (llegando incluso a tener tintes violentos en su versión más parecida a las "bandas" de delincuentes), donde se hallan escritores de prestigio, con experiencia y un nivel acreditado entre la comunidad de grafiti mezclados con jóvenes aprendices que empiezan a destacar (De Diego, 2000, 80) o que han realizado alguna acción que les ha validado el acceso. La base de acceso a la crew es la afinidad y, por encima de ella, la habilidad, tenacidad y la capacidad de correr riesgos.

Hasta la actual era digital eran fundamentalmente localistas. Se formaban en círculos geográficos de proximidad y se relacionaban mediante viajes con homólogas extranjeras, a modo de estancias (entendida la palabra casi de forma 
académica) de un miembro o varios en otras ciudades. Así se establecían redes, pintaban junto a otras personas, exportaban su estilo e importaban a su vuelta nuevas maneras, convirtiendo a su crew en internacional.

Este modo de asociacionismo viajero sigue plenamente vigente, pero con una gran variación. El modo de contacto actual, el fichaje de nuevos miembros e incluso la hermandad directa con otra crew se puede hacer ya de forma virtual. El intercambio de imágenes en redes sociales, de likes, etc., constituyen el primer contacto. De esta conexión virtual nacerán alianzas prácticamente indisolubles que permitirán que se genere un muy importante turismo de grafiti. Un buen ejemplo es el caso de la crew The Crime Kings (TCK), que es de raíz madrileña; está activa desde finales de los años 80 de forma ininterrumpida y se ha expandido, al menos su nombre, de Madrid a lugares como el Soho en Nueva York.

Las crews han encontrado en la era digital a través de la plataforma YouTube un medio de publicidad sin igual. Importar fotografías está bien y es necesario para el juego, pero la posibilidad de tener un canal donde colocar vídeos -cada vez con más trabajo de edición, duración y calidad- no se puede desperdiciar. Los canales habitualmente privados -pero de fácil ingreso- funcionan como una agencia de autopromoción de la crew. En ellos cuelgan todo tipo de material que documenta sus acciones y sirven tanto para mostrarse ante sus crews hermanas como para retar a crews enemigas.

Un canal importante en el mundo del grafiti es el que la propia casa de pinturas Montana Colors tiene en dicha plataforma llamado MontanaColorsTV ${ }^{4}$. Este canal no precisa de invitación previa y en él la casa de pintura especial para grafiti cuelga vídeos de escritores a los que promociona en sus viajes por todo el mundo. Ejemplo de ello es el que realizó en 2014 el grafitero canadiense APER. A modo de Grand Prix, APER viajó por toda Europa -según reza en la información del vídeo- deteniéndose a pintar algunos trenes de Roma y Mallorca. Al recalar en la isla contó con la ayuda de escritores locales (como DASE, Tiros y Bomba) tal y como se explica en la descripción del vídeo que la compañía de pintura publicó en septiembre de 2014.

\section{INTERCONECTIVIDAD Y GRAFITI: CUESTIONES LEGALES}

La difusión es, por tanto, una ventaja potente en el juego del grafiti. Pero trae consigo una desventaja, porque en el mundo digital toda importación deja una huella indeleble, rastreable y, por ende, perseguible.

${ }^{4}$ Vid. https://www.youtube.com/watch?v=ShYqIHZn0CM. Visualizado en 04-01-2019 a las 13:30h. 
Hasta hace unas décadas los grafitis se rastreaban de forma física, mediante técnicas caligráficas y exámenes organolépticos sobre el terreno. Al ser tan artesanales los procedimientos se dilataban en el tiempo en beneficio de los grafiteros. En la actualidad los grupos de investigadores de los distintos cuerpos de seguridad del Estado poseen, además del experto caligráfico, la figura del rastreador o experto que recaba datos en diversas redes para así aportar más información pericial en los informes.

La interconectividad supone un cambio sustancial en la manera de procesar una falta administrativa elevándola en la mayoría de los casos a delito penal por su magnitud.

En el pasado al grafitero se le podían imputar en un caso aproximadamente tres o cuatro piezas. Si el escritor era hábil y cambiaba la firma e incluso la radicación de las obras (pintar en otro barrio, en el extrarradio, etc.) tardarían mucho en procesarlo o podría llegar a salir indemne.

¿Qué sucede ahora? en un alarde ególatra acorde con la naturaleza de su juego el grafitero ha subido a diversas plataformas todas las imágenes de sus piezas, ha incluso posicionado con su móvil el lugar en que ha realizado las mismas y ha dejado una huella tan fuerte que facilita el rastreo. La policía, en innumerables ocasiones, no necesita salir corriendo tras el grafitero al que ha cogido in fraganti, sino que espera paciente visualizando y registrando cada actuación, catalogándolas hasta conformar una diligencia completa y demoledora para el escritor, ya que en ella pueden encontrarse de 20 a 30 intervenciones que encarecerán la multa e incluso podrían elevar a penal el caso.

A tal efecto es importante apuntar una noticia relativamente reciente (abril de $2018^{5}$ ) de una gran multa y un gran dispositivo policial en el que han intervenido los cuerpos de seguridad de la ciudad de Nueva York, la Interpol y la policía nacional española. Los tres cuerpos de forma coordinada cotejaron los grafitis de tres ciudadanos españoles que se habían trasladado a Nueva York para pintar en su red ferroviaria ${ }^{6}$. Para tal dispositivo y resolver el caso ha sido necesario contar con numerosas herramientas y cotejar imágenes de todas las agencias. Nuevamente, la huella digital ha hecho su parte en el juego, dejando hasta el momento la que se apunta puede ser la multa más cara de la historia.

En definitiva, la era digital ha pulverizado también las fronteras que existían entre el yo-escritor-de-grafiti y el yo-ciudadano-internauta, y en este punto se hace imposible disociar ambos yoes del yo-ciudadano-sometido-a-las-normas$y$-a-la-ley, porque la privacidad de la identidad queda completamente anulada.

\footnotetext{
5 https://www.elespanol.com/espana/20180421/detienen-espanoles-acusados-pintargrafitis-nueva-york/301469894_0.html. Visualizando en 04-01-2019 a las 14:00h.

${ }^{6}$ Vid. https://www.elespanol.com/espana/20180421/detienen-espanoles-acusados-pintar-grafitis-nueva-york/301469894_0.html consultada en 30-01-2019 a las 20:52h.
} 
Sin embargo, el juego sigue porque las multas no menguan el ánimo de los escritores. El premio es ahora mayor de lo que era en el grafiti primigenio de los años 70, el preciado Hall of fame de entonces, ya que ahora aquel muro perfecto con la pieza perfecta se encuentra en cualquier lugar y a un clic de distancia. El muro físico existe y hay que conquistarlo, pero para mayor gloria está el metafórico muro virtual. Llegados a este punto internet y las plataformas que en él habitan se han convertido en una suerte de "Salón de los rechazados", porque acoge las importaciones de todo tipo de manifestación con o sin pretensión artística.

\section{LA ERA DIGITAL, ¿LA ERA DE LA PRODUCCIÓN EN SERIE?}

Si algo fascina a quienes estudiamos el fenómeno del grafiti y que ya ha sido comentado antes, es el hecho de que se haya mantenido prácticamente invariable (en cuanto a técnica, temática y materiales) desde hace casi cincuenta años. Media centuria conservando todos los elementos que lo conforman sin variar ni uno, aún con el paso de varias generaciones y el salto al resto de países del mundo. Se podría afirmar que en el grafiti todo está inventado. Las tipografías ya están todas experimentadas y expuestas ${ }^{7}$ desde el nacimiento del grafiti, desde las electrizantes, a las puntiagudas, a las de estética geométrica, la burbuja, etc., así como las ornamentaciones (flechas, lanzas, coronas, círculos, estrellas, puntos, etc.).

La magnificación que supone la consolidación del mundo global nos hace plantearnos cuestiones tan importantes como la de la originalidad y seriación. El escritor de grafiti en el momento en que decide serlo elige un seudónimo que va a marcar en gran medida su suerte en este juego comunicativo. El escritor debe poder asumirlo artísticamente y debe ser capaz de defenderlo con un estilo propio y una caligrafía trabajada. Todo ello, como ya se ha comentado, educado de modo artesanal en el black book. Desde esa primera elección se le exige originalidad, no es una elección inteligente copiar un seudónimo porque ello va a tener consecuencias desagradables y ese escritor quedará rápido fuera del juego.

En cuanto a la caligrafía también se exige originalidad, tener un estilo que te defina a la perfección como escritor es uno de los objetivos que debe superar todo grafitero: hacer algo que nadie más hace y hacerlo bien.

En cuanto a las piezas, aunque el seudónimo sea siempre el mismo, no hay dos piezas iguales, no se trabaja en serie, no se realizan trabajos idénticos, por lo que cada pieza debe ser diferente a la anterior.

7 Vid. https://www.youtube.com/watch?v=NFBRfhoAB1Q. Quedan expuestas las tipologías que hoy perviven. Visualizado en 05-01-2019 a las 15:10h. 
En la era analógica previa a la democratización de la información en internet los escritores se diferenciaban por esas cuestiones, ya que, el dominio y el estilo son razones fundamentales de diferenciación de autores. Ejemplo de ello son las letras burbujeantes del escritor OVAS afincado en Mallorca, o la tipografía electrizante y en permanente descomposición de estilo cubista del también escritor mallorquín DISOH. Ambos autores son reconocibles a simple vista, como también es fácil de observar la diferencia entre cada una de sus piezas a pesar de utilizar siempre el mismo seudónimo.

Anteriormente la difusión era muy reducida. Solamente veían las piezas aquellos que estaban alrededor de un escritor, quienes las buscaban hasta dar con ellas (otros escritores) y quienes accidentalmente daban con ellas en una ciudad a lo largo de su vida. El público era limitado y todo parecía tener una capa de originalidad que lo recubría. Sin embargo, y si miramos el mundo virtual que hemos construido, esa capa de originalidad parece desaparecer. En todas partes hay escritores que optan por las letras burbuja por ejemplo y en todas partes son iguales. Lo mismo sucede con el resto de las tipografías. Varían los colores, la disposición de la obra en el muro, pero no la técnica.

La originalidad parece perderse en el mundo digital o se sustituye por el concepto de trabajo en serie. Todas las piezas se parecen entre sí, todas comparten la misma técnica algunas con mejor resolución que otras, pero entre las que son brillantes no hay diferencia. Si dispusiéramos todas las piezas en una sola galería de imágenes parecería que se ha realizado una producción en serie.

Así pues, se llega a la conclusión de que para encontrar otra vez la originalidad perdida y recuperar la frescura de la pieza única hay que dejar de mirar al exterior y mirar de nuevo al interior. Solo apreciamos genialidad y singularidad en tanto en cuanto nos ceñimos a contextos locales porque una vez miras al mundo -en toda su extensión- aprecias seriación en el grafiti.

No obstante, esto, que podría suponer un inconveniente o hándicap para el grafiti no hace más que reafirmar la fascinación ante una manifestación que persevera en su propia naturaleza. Resulta aún más sorprendente que siga siendo -literalmente- la misma práctica que salió de aquel Nueva York marginal y mestizo de 1970 la que nos ha llegado al tiempo presente.

\section{CONCLUSIONES}

A modo de conclusión o cierre, recapitulemos ciertos aspectos expuestos.

En primer lugar, la consideración de grafiti como ejercicio de comunicación, como conversación entre diversos agentes a diferentes niveles. Con mayor o menor grado de conciencia todos intervenimos -incluso cuando no lo hace- 
mos- en el grafiti como discurso en los muros y el grafiti se cuela en el imaginario colectivo de los ciudadanos a fuerza de ser visto.

En segundo lugar, la fuerza perseverante del grafiti, que ha sido capaz no solo de sobrevivir al paso del tiempo sino de consolidarse de una generación a otra dando lugar a una lista de autores casi interminable desde hace cincuenta años. Todo ello unido a la homogeneidad con la que se ha expandido universalmente y sin perder en ningún momento ni lugar ni un ápice de su idiosincrasia.

En tercer lugar, la capacidad de adaptación a las nuevas tecnologías, que ha sido y está siendo admirable, ya que el uso que hace de ellas responde únicamente a fines internos de grafiti, no se busca un rédito de otro tipo ni tiene otras pretensiones que no sean la ya consabida fama del escritor.

Pese al efecto legal negativo que trae consigo la utilización de herramientas digitales el grafiti sigue sobreponiéndose, sigue empleándose a fondo en su supervivencia, manteniéndose en el lado oscuro fiel a la ilegalidad que le otorga carta de naturaleza y que por supuesto atrae a esas nuevas generaciones de jóvenes escritores y que mantiene en activo a los más veteranos.

En cuarto lugar, cabe reincidir una vez más en los aspectos positivos que ha traído consigo la interconectividad en el mundo del grafiti y en su producción, porque la capacidad de conexión mundial posibilita que las obras se multipliquen internacionalmente, que los autores viajen de un lugar a otro dejando su huella, compartiendo técnicas y expandiendo los dominios de unas crews que carecen ya de barreras. Resulta muy evidente el trasvase de ideas al visualizar diferentes grafitis de diversas partes del mundo, los intercambios de ideas e imágenes han posibilitado no sólo conocimiento sino también la asunción de modelos muy comunes en un sitio y muy poco en otro.

Finalmente, la era digital y el mundo conectado suponen muchos y diversos adelantos, pero para quienes nos proponemos estudiar estas manifestaciones significa una suerte de archivos digitales, un abanico inmenso de posibilidades de estudio que van más allá de unos rasgos comunes o de unos procesos técnicos parecidos, ya que nos permite establecer una especie de estética, ética y teoría del arte del grafiti, gracias precisamente a las bondades ocasionales de la globalización. Es un ejemplo preciso la posibilidad de establecer contacto digital entre escritores locales (como los mallorquines Lais y Sem) y escritores extranjeros (Altes y Berny, a modo de ejemplo) porque ambos perfiles conectan con la disciplina aunque estén separados geográficamente.

Por ello es posible afirmar que se pueden conocer nuevas sensibilidades de otros lugares sin desplazarnos y se puede acceder a un gran fondo digital de imágenes, sin el cual, muchas ya se habrían perdido para siempre. 


\section{BIBLIOGRAFÍA}

ABARCA, J. (2010): El postgraffiti, su escenario y sus raíces: graffiti, punk, skate y contrapublicidad (tesis doctoral), Universidad Complutense, Madrid, p. 35.

BAUMAN, Z. (2004): Modernidad líquida, Argentina, Fondo de cultura económica, p. 111.

BERTI, G. (2009): Pioneros del graffiti en España, BPR Publishers.

BLUME, R. (1985): “Graffiti”, en Discourse and Literature, 3, pp. 137-148.

COOPER, M., CHALFANT, H. (1984): Subway Art, New York, An Owl Book.

DE DIEGO, J. (2000): Graffiti: la palabra y la imagen, Barcelona, Los Libros de la frontera.

DJUKICH, D., FINOL, J.E. (1996): "Semiótica del Discurso Amoroso: El graffiti en la prensa", paper presentado en el Centro Internacional de Semiótica y lingüística de la Universidad de Urbino, Italia.

FIGUEROA, F. (2006): Graphitfragen. Una mirada reflexiva sobre el graffiti, Madrid, Minobitia.

FIGUEROA, F. (2014): El grafiti de firma: Un recorrido histórico-social, por el grafiti de ayer y hoy, Madrid, Minobitia.

GÁNDARA, L. (2003) Graffiti, Buenos Aires, Universitaria de Buenos Aires, p. 11.

GANZ, N. (2004): Graffiti: arte urbano de los cinco continentes, Barcelona, Gustavo Gili.

GARÍ, J. (1995): La conversación mural. Ensayo para una lectura del graffiti, Madrid, Fundesco.

JÓDAR, J.A. (2010): "La era digital: nuevos medios, nuevos usuarios y nuevos profesionales", Razón y palabra, 15 (71), pp. 1-12.

PEREIRA, S. (2005): Graffiti, United Kingdom, Silverback Books.

\section{FILMOGRAFÍA}

CHALFANT, H., SILVER, T. (1983): Style wars (Guerra de estilos).

\section{Recursos Web}

https://www.elperiodico.com/es/sociedad/20180421/detenidos-tres-grafiteros-espanoles-en-nueva-york-por-pintar-en-el-metro-6774020

https://www.elespanol.com/espana/20180421/detienen-espanoles-acusados-pintargrafitis-nueva-york/301469894_0.html

https://www.elespanol.com/reportajes/20180716/grafiteros-pintan-trenes-adrenalinasanciones-peligro-muerte/322718020_0.html

https://www.elespanol.com/reportajes/20180704/grafiteros-aterrorizan-conductores-

barcelona-piedras-pistolas-taser/319719019_0.html

https://www.heraldo.es/noticias/aragon/zaragoza/2015/03/15/quien-el-sope-345451-

2261126.html

https://www.instagram.com/thecrimekings_tck/

https://elpais.com/ccaa/2018/11/07/madrid/1541568318_190065.html

https://www.youtube.com/watch?v=NFBRfhoABlQ 